\title{
Oralidades em anotações de cordel: a produção de diários poéticos em
} aulas de escritura acadêmica ${ }^{1}$

Fábio Soares da Costaㄹ, Rosa Maria Rigo ${ }^{3}$, Maria Inês Côrte Vitória ${ }^{4}$, Andreia Mendes dos Santos ${ }^{5}$

\begin{abstract}
Resumo
Este texto objetiva apresentar contribuições da produção poética da literatura de cordel no desenvolvimento do ler e escrever durante disciplina curricular de escritura acadêmica em nível stricto sensu das Ciências Humanas, área de Educação. Conceituações e contribuições da tradição, oralidade e regionalismo literário foram abordadas como fundamento para a compreensão do ato dialógico da investigação, relacionando a transversalidade da escritura poética e acadêmica como possibilidade de aprendizagem e como abordagem teórico-metodológica para registro, avaliação e compreensão dos conteúdos/discussões próprios da comunicação científica. O prosaico da academia entrelaçado com a poética da tradição nordestina emerge como forma de motivação para a produção de textos, no entre lugar do deleite e da forma, como estratégia pedagógica de leitura e escrita. A escrita de cordéis, durante as vivências do currículo acadêmico, promoveu aprendizagem alicerçante para ler e escrever na academia científica. Assim, concluiu-se que o agente poético do cordel extrapola o prazer do lido, permite compreensão necessária da forma escriturária científica, fomenta uma cultura leitora e oferece possibilidades de fazê-la em alternância de leituras e escritas. Relatos da experiência da escrita de cordéis, neste estudo, apontam para a necessidade de considerar este recurso literário poético regional como profícuo para a escritura acadêmica.
\end{abstract}

\section{Palavras-chave}

Diários de Aula. Escritura Acadêmica. Literatura de Cordel.

1. Uma versão inicial deste texto foi publicada nos Anais do Seminário Brasileiro de Crítica Literária da Pontifícia Universidade Católica do Rio Grande do Sul.

2. Doutorando em Educação na Pontifícia Universidade Católica, Rio Grande do Sul, Brasil. E-mail: fabio. costa.002@acad.pucrs.br.

3. Doutoranda em Educação na Pontifícia Universidade Católica, Rio Grande do Sul, Brasil. E-mail: rosa.rigo01@ gmail.com.

4. Doutora em Reformas e Inovações no Processo Educacional pela Universidad de Santiago de Compostela, Espanha; professora da Escola de Humanidades da Pontifícia Universidade Católica, Rio Grande do Sul, Brasil. E-mail: mvitoria@pucrs.br.

5. Doutora em Serviço Social pela Pontifícia Universidade Católica do Rio Grande do Sul, Brasil; professora da Escola de Humanidades da Pontifícia Universidade Católica, Rio Grande do Sul, Brasil. E-mail: andreia.mendes@ pucrs.br. 


\title{
Oralities in cordel notes: the production of poetic diaries in classes academic writing
}

Fábio Soares da Costa*, Rosa Maria Rigo**, Maria Inês Côrte Vitória***, Andreia Mendes dos Santos ${ }^{* * *}$

\begin{abstract}
This text aims to present contributions of the poetic production of cordel literature in the development of reading and writing during curricular discipline of academic writing in stricto sensu level of Human Sciences, Area of Education. Conceptualizations and contributions of tradition, orality and literary regionalism were approached as a basis for the understanding of the dialogical act of research, relating the transversality of poetic and academic writing as a learning possibility and as a theoretical and methodological approach for recording, evaluating and understanding the contents / discussions of scientific communication. The prosaic of the academy intertwined with the poetics of the Northeastern tradition emerges as a way of motivating for the production of texts, in the interlace of delight and form, as pedagogical strategy of reading and writing. The writing of cords, during the experiences of the academic curriculum, promoted a literary learning to read and write in the scientific academy. Thus, it was concluded that the poetic agent of the cordel extrapolates the pleasure of the read, allows necessary understanding of the scientific writing, foments a reading culture and offers possibilities to do it in alternation of readings and writings. Reports from the experience of writing cords in this study point to the need to consider this regional poetic literary resource as useful for academic writing.
\end{abstract}

\section{Keywords}

Classroom Diaries. Academic Writing. Literature of Cordel.

\footnotetext{
* PhD student in Education, Pontifical Catholic University, State of Rio Grande do Sul, Brazil. E-mail: fabio. costa.002@acad.pucrs.br.

**PhD student in Education, Pontifical Catholic University, State of Rio Grande do Sul, Brazil. E-mail: rosa.rigo01@ gmail.com.

*** PhD in Reforms and Innovations in the Educational Process, University of Santiago de Compostela, Spain; professor at the School of Humanities, Pontifical Catholic University, State of Rio Grande do Sul, Brazil. E-mail: mvitoria@pucrs.br.

**** Phd in Social Service, Pontifical Catholic University, State of Rio Grande do Sul, Brazil; professor at the School of Humanities at the said institution.E-mail: andreia.mendes@pucrs.br.
} 


\section{Introdução}

As reflexões aqui desenvolvidas têm como principais tributárias as vivências e experiências no decurso das aulas de escritura acadêmica desenvolvidas em curso de pósgraduação em educação, a nível stricto sensu. Esses momentos, entrecruzados ao regionalismo nordestino, vívido em nós, possibilitaram a construção coletiva de escritos poéticos em forma de cordel a partir de conteúdos relativos à escrituração acadêmico-científica.

A existência de um insight foi clara: será que a forma tão dura, formatada e normativa da escrita de textos acadêmicos poderia se relacionar com uma literatura poética leve, aberta, fluida e repleta de novas possibilidades, como o cordel? Se houver essa possibilidade, como exercê-la? Qual seu produto e sua contribuição para o campo do ensino/educação?

A escrita acadêmica e do cordel são processos que se desenvolvem a partir de lógicas linguísticas e culturas de escrita diferenciadas, não obstante, tem como fato comum a palavra. Aqui, percebida em sua dualidade possível, assim como discerne Marcos Villela Pereira (2013), representada tanto pela prisão do pensamento, quanto pela sua liberdade. Neste itinerário, nos importa o mesmo que para o autor, a palavra escrita. A primeira e mais forte ligadura entre a escrita acadêmica e de cordel.

De fato, escrevemos para o leitor, mas para nós mesmos em concomitância. Daí, mais uma possível amálgama entre os tipos de escrito, pois ambos pressupõem um leitor atento, apto à conversão do código em sentidos, interessado no novo semântico, alheio ou consolidador de suas (in)certezas.

A intitulação "anotações de cordel" designa a produção literária possível ao longo de um semestre letivo. Durante as aulas de escritura acadêmica foram criados cordéis tendo como pressuposto temático a escrita das ciências. O conteúdo curricular apresentado de forma diversa (aulas expositivas dialogadas, com uso de recursos tecnológicos, por seminário, com uso de quadro e giz, com práticas e trabalhos em grupo) foi, também, representado na forma de literatura de cordel pelo lado receptor/construtor dos saberes em aula.

Este relato de experiência descortina as impossibilidades de relação entre a dureza da forma e a leveza da poética em um ambiente marcado pelas exigências da inteligibilidade, assim como Fischer (2005) desenvolveu ao tratar da experiência da criação e da fruição estéticas e a produção do texto acadêmico, evocando Derrida e a perspectiva de uma "leitura assinada", com marcas de um "engenho da arte".

Ao leitor, dedicamos dois esforços: o primeiro, de desenvolver uma conexão produtiva, coerente e de ensino, a existir entre a escrita da ciência e a produção literária de cordel; o outro, de apresentar excertos da produção desenvolvida nas aulas de escritura acadêmica, alinhavada entre o conteúdo curricular e a estética literária.

Todavia, não é pretensão desse exercício dialógico a conversão da literatura como escrita das ciências, ao contrário, suas especificidades não são postas em tensionamento aqui. O que se pretende é apresentar a escrita do cordel como diário de aula, momento de deleite, motivador e de gatilho para a compreensão de conteúdos curriculares relacionados à escrituração na academia.

\section{A escritura acadêmica}

A escrita de textos no cotidiano acadêmico é percebida por meio de suas singularidades, inclusive com variância entre os diferentes níveis de ensino. No ambiente universitário, sua cobrança acontece desde os primeiros contatos entre alunos e professores, que os exigem, apesar da pouca familiaridade dos estudantes. 
Este contexto gera discordâncias, frustração bilateral e uma sensação, por parte do aluno, de que a escrita deve ser desenvolvida apenas por obrigação. Ainda, as queixas por parte de professores e de alunos quanto à dificuldade de produção de textos acadêmicos é uma constante.

No Brasil, a produção de textos acadêmicos, sobretudo no nível universitário, acontece por sua necessidade, pois teses, dissertações, monografias e artigos são produtos e processos deste nível de ensino, devendo ser aprendidos, não só, mas principalmente nele. Essa aprendizagem nos remete ao conceito de comportamento social desenvolvido por Bakhtin (1997), na qual a experiência, como processo constitutivo é essencial para o domínio de um gênero linguístico, é condição primária no aprendizado contextualizado.

A resistência ao ato de escrever, percebida em universitários, como apontam Vitória e Christofoli (2013, p. 41), distancia o sujeito da produção de um texto. Neste estudo, as autoras perceberam que:

pressuposto 1 - há ruptura da ideia de coerência entre o que pensamos, o que conseguimos escrever, o que entende nosso interlocutor; pressuposto 2 - a autocorreção de textos como exercício de pesquisa é imprescindível para a qualificação da escrita; pressuposto 3 - os diários de aula representam rico instrumento para a qualificação da escrita no Ensino Superior; pressuposto 4 - há necessidade de que o aluno do Ensino Superior escreva variados tipos de escrita, ainda que a universidade cumpra com seu papel, enfatizando a escrita acadêmica; pressuposto 5 - o trabalho com a escrita no Ensino Superior deve enfatizar os componentes básicos da expressão escrita: o código escrito e a composição da escrita.

Desses resultados, os pressupostos 3 e 4 fizeram-nos produzir os cordéis como forma de materialização dos diários de aula e exercício de outras formas de escrita, como perspectiva de deleite, assim como estímulo à auto percepção sobre nossas competências e habilidades para escrever.

As autoras ainda ressaltam que $\mathrm{O}$ acesso à leitura, as vivências pessoais do aluno e sua relação com o que se escreve, sua capacidade de inferência e a atitude do professor de fazer um uso social das escritas, são basilares para um aumento no repertório de linguagem escritural acadêmica de alunos em nível superior. Ainda, se algumas práticas pedagógicas relacionadas à escrita podem ser responsáveis pelo distanciamento entre o aluno e a própria língua, por distância da sua realidade e vivência, outras podem motivar, provocar deleite, instigar o prazer por uma produção textual, ao mesmo tempo, crítica e prazerosa.

Durante um semestre letivo foram produzidos cordéis em todas as aulas da disciplina de Escrita Acadêmica ofertada por um curso stricto sensu de Mestrado/Doutorado em Educação de uma instituição educacional do Estado do Rio Grande do Sul. A produção dos cordéis era sempre sucedida por sua declamação. Assim, a oralidade se materializava como socialização da produção poética em dinamismo e entrelaçamento com a escrita acadêmica, pois a tematização dos cordéis era a mesma da aula ofertada, tratando-se, desta forma, das potencialidades na escrita de textos acadêmicos.

\section{0 cordel}

De caráter narrativo, o cordel é um produto poético literário de natureza popular. Geralmente aborda temáticas regionais nordestinas ligadas à realidade do espaço/ tempo, mas também com inúmeras produções ficcionais, imaginadas de "causos"s, lendas, fábulas e mitos, contadas de geração em geração nordestina, desde o período colonial. Tem forte ligação com outra cultura nordestina

5. Causos são histórias, reais ou ficcionais, contadas de forma engraçada e de objetivo lúdico, compondo o folclore brasileiro regional. 
- o repente ${ }^{6}$, pois seu início foi caracterizado pela produção oral, apenas. Posteriormente, passou a ser concebido nas formas escrita e impressa em folhetins, caracterizado pelo desenvolvimento de versos com rima, ilustrados por xilogravuras (FONSÊCA; FONSÊCA, 2008).

Para os autores, a denominação cordel se dá pela forma como eram expostos para venda em Portugal, pois sua origem é europeia. Pendurados em cordões, eram comercializados em feiras, mercados e praças. No nordeste brasileiro, foi introduzido pelo estado da Bahia, em época de colonização, e hoje, apesar de ser caracteristicamente nordestino, difundido, consumido e produzido, sobretudo nos estados da Paraíba, Ceará e Pernambuco, já é conhecido nacionalmente como produção/literatura poética brasileira.

A linguagem do cordel é simples e popular. Possui métrica e ritmo próprios, contudo, de fácil compreensão dos leitores. Suas temáticas são territorializadas, mas diversas. Isso possibilitou que a escritura acadêmica fosse uma delas. A maioria dos cordéis abordam temas sociais, o que nos estimulou a perceber sua aplicação em ambiente escolar, para a formação de professores, pois a abordagem histórica, política, econômica e, aqui, as questões que envolvem a escrituração acadêmica, podem ser despertadas, experimentadas, vividas de um ponto de vista crítico, a partir da escrita de cordéis. Esse posicionamento é ancorado na perspectiva de Silva e Arcanjo (2012) que aproxima a produção do cordel a temas emergentes, relacionados estreitamente com a realidade social.

Para Bezerra (2015, p. 11),

O texto escrito tem função comunicativa, discursiva e até mesmo linguística específica; dessa maneira, para sua produção é necessário um conhecimento de vários outros gêneros textuais, sejam eles orais ou escritos. O Cordel é construído de acordo com a finalidade e a intenção da produção; além de entreter, pela linguagem simples e rimas envolventes, traz reflexões significativas, ao discutir temas relacionados a dilemas humanos, inovando, renovando e se reorganizando a cada geração que o produz; exemplo claro é o Cordel contemporâneo, no qual são trabalhadas obras literárias, temas sociais, violência dentre outros.

Para a autora, o cordel tem valor em processos educacionais por sua beleza literária, envolvente para a leitura, estimulante para a escrita, com possibilidades de expressão pessoal crítica e reflexiva. Extrapola a função pragmática e simbólica da decodificação. Para além, entretém, dá prazer, promove um deleite estimulante para sua leitura e escrita. Aqui, percebeu-se o estímulo para a escrita acadêmica, pelo reconhecimento pessoal das habilidades e competências individuais para sua escrita.

\section{Forma: métrica e rima}

A Academia Brasileira de Literatura de Cordel (2016) apresenta os tipos, formas e características dos cordéis, levando em consideração seu percurso histórico, variações, surgimentos e ressurgimentos de alguns estilos. Todavia, atentaremosàscaracterísticasdoscordéis desenvolvidos nas aulas de Escritura Acadêmica.

A evolução literária do cordel foi harmoniosa e se iniciou na transferência da oralidade para a escrita, até sua estrutura formal de hoje, livre, mas estruturada. O início se deu com a parcela ou verso de quatro sílabas: curta e fácil de ser cantada. Posteriormente surgiram os versos de cinco sílabas, inaugurado por Firmino Teixeira do Amaral, que tinha como principais características sua cantoria com o ritmo acelerado, exigindo do repentista grande rapidez de raciocínio (ABLC, 2016).

As quartas, estrofes de quatro versos e sete sílabas, são as mais comuns entre iniciantes em escrita de cordel e foram desenvolvidas nas aulas de Escritura Acadêmica, como no exemplo

6. Repente é uma declamação poética desenvolvida por invenção imediata, improvisada, repentina 
a seguir, do cordel Orienta dor:

\author{
Uma estória vou contar \\ de quem um dia ouvi falar. \\ Um orientador desumano \\ a quem eu queria matar.
}

Uma questão importante no cordel é que a construção dos versos é desenvolvida a partir de uma contagem de sílabas poéticas. Nessa contagem, permite-se reunir duas sílabas em uma só como na crase (sinalefa) e contrair duas sílabas numa só sem alteração de letras (sinérese). É uma liberdade própria deste estilo.

As sextilhas, orientadas para os grandes poemas romanceados, é a forma mais consagrada pelos cordelistas. Nelas, o que mais acontece é a rima entre o segundo, o quarto e o sexto versos, deixando órfãos: o primeiro, o terceiro e o quinto versos. Para a ABLC (2016, p. 1), "É a modalidade mais rica, obrigatória no início de qualquer combate poético, nas longas narrativas e nos folhetos de época" e pode ser apresentada em cinco estilos: aberto, fechado, solto, corrido e desencontrado. Nas aulas de Escritura Acadêmica, foram produzidas sextilhas abertas, fechadas e soltas, como a seguir:

Sobre a escrita de um artigo (cordel de sextilha aberta)

Primeira linhas, sinto

um medo de estremecer,

e, às vezes, minto

por não entender

que a escrita é uma prática

para um vir a conhecer.

Turma de Escritura (cordel de sextilha fechada)

Da imagem, um belo retrato

de leitura e escritura.

Uma mensagem de agrado

e também de travessura,

de querências deste Sul amado,

de lindas gurias e formosura.

De repente um desejo de poema (cordel de sextilha solta)

\author{
Ah escrita! Querida escrita. \\ De versos e estrofes, \\ de contos e prosa. \\ Do mais singelo ato de sonhar \\ e com letras cifrar músicas \\ falar e com o coração amar.
}

As setilhas são estrofes de sete versos de sete sílabas. Criadas por José Galdino da Silva Duda (1866-1931). Essa forma teve como maior expressão José Pacheco da Rocha (1890-1954), com o poema A chegada de Lampião no inferno. Muito usada pelos cordelistas em festas e feiras, pode variar entre sete, oito e dez versos.

Ainda possui destaque pela ABLC (2016) os estilos: oito pés de quadrão ou oitavas; as décimas; o martelo agalopado; o galope à beira mar; e a meia quadra. Todavia, essas formas de cordel não foram lidas nem produzidas nas vivências, não sendo, portanto, nosso foco de discussão.

\section{A produção cruzada: oralidades em anotações de cordel}

Nos últimos anos, muitas produções acadêmico-científicas vêm apresentando, vivenciando e experimentando a produção literária do cordel como método de ensino. Silva Filho (2010), Fonsêca e Fonsêca (2008) e Silva e Arcanjo (2012) são alguns desses exemplos. Entretanto, este não é nosso reforço ou cotejamento, mas a apresentação de uma linguagem escrita que proporcione deleite e, assim, estimule o ato de escrever, potencializando a escrita acadêmica, como estilo díspar, mas também, prazeroso no cotidiano acadêmico.

As vivências nas aulas de escritura acadêmica foram iniciadas em março de 2016 e concluídas em julho do mesmo ano. Nesse período, muitas atividades pedagógicas foram realizadas com o objetivo de atender as necessidades de aquisição de fluência e domínio do processo de elaboração de argumentos 
científicos através da escrita acadêmica; melhorar as habilidades de expressão escrita e de organização textual; e socializar experiências sobre a escrita acadêmica entre os que se encontram em fase de preparação de apresentação pública da sua pesquisa em situações de defesa de projeto, dissertação e tese.

Este percurso nos fez perceber que diários de aula, assim como Zabalza (2004) os concebe, como instrumento de registro do aluno e também como recurso de qualificação da escrita, poderia ser uma profícua alternativa para o desenvolvimento da disciplina, para um registro prazeroso, estruturado e organizado dos conteúdos abordados no caminho, assim como forma textual que pudesse motivar novos escritos e estimular a leitura em outros acadêmicos. Para isso, elegemos a escrita de cordéis para construir nossos diários de aula.

Neste contexto, a perspectiva de produzir diários de aula (ZABALZA, 2004), em forma de cordel, para compor o conjunto de atividades acadêmicas da disciplina Escritura Acadêmica, notabilizou-se em nós como recurso para um pensamento autodeterminado (APPEL-SILVA; WENDT; ARGIMON, 2010), metodologia ativa para o deleite de leitura e escrita e forma estruturada para anotação e revisão dos conteúdos curriculares desenvolvidas ao longo da disciplina.

A seguir, a produção literária de cordel ilustra parte da constituição desses diários de aula poéticos, construídos em sala de aula, durante as atividades didáticas desenvolvidas a partir do conteúdo programático, ementa e estratégias pedagógicas.

\footnotetext{
Primeiras Escritas

Experiências com a escrita reminiscências ditas escritas e reescritas de uma vida a ser lida

Como se pudesse de uma vida tirar fragmentos da escrita
}

recordar travessuras tidas

de uma história deveras rica

Comunidades Discursivas

Conversas:

Respostas e perguntas,

dúvidas e incerteza.

Em alerta, o grupo assunta

contos e causos com clareza.

Um assunto se destaca:

discursos e comunidades.

As comunidades discursivas,

controvérsias, mitos e verdades.

Pensamentos:

objetivos e abstratos

Usos: códigos e cognatos

Formas: círculos e quadrados

Discursos: signos e enunciados

\section{Considerações finais}

A escrita acadêmica possui, por primazia, a função de produzir conhecimentos, além de materializar, pela linguagem escrita, o que os alunos querem dizer de suas vivências, experiências e reflexões, durante os estudos. Percebemos, em nossas vivências com a produção poética de cordéis sobre escritura acadêmica, que não se trata de forma, modelo, receita ou protocolo para se produzir uma "boa escrita", mas sim de relação, uso social, deleite, motivação, autodeterminação e prazer em escrever, diversos gêneros textuais, para bem se escriturar nas/das ciências. $O$ percurso disciplinar na escritura acadêmica nos fez perceber que a imersão na leitura, de vários gêneros textuais, com atenção para reflexão e análise, possibilitou a escrita de outro gênero textual (cordel), que não a escrita acadêmico-científica, promovendo maior adaptação às distintas formas culturais de escrever e, consequentemente, motivando, pela autodeterminação, a escrita acadêmica, como a deste texto.

Um discernimento nos parece necessário 
às nossas considerações finalísticas: a de que, em concordância com Pereira (2013), nos escritos acadêmicos, notadamente diversos e com forma nuclear díspar aos escritos literários e poéticos. Devemos atentar aos cuidados com as licenças poéticas que, por vezes, inseridas na forma de metáforas e variações estéticas linguísticas, podem mais atrapalhar que promover o entendimento razoável ao objeto que se estuda. Este adendo é necessário para o entendimento de que os resultados promovidos pela produção de cordéis a partir de conteúdos de escrita acadêmica potencializam em nós a produção de diários de aula mais deleitosos, instigantes e reflexivos, não sendo intensão a mescla/inserção deste gênero/estilo textual aos escritos acadêmicos de nível superior.

Esse processo possibilitou a construção do Cordel da Escritura Acadêmica, produto literário poético com temas relacionados às aulas de escritura acadêmica, socializado com professores e alunos do stricto sensu e graduação. Um conjunto de textos que teve como principais atributos contribuintes para a escritura acadêmica: 1) aumento na familiaridade com o ato de escrever (mesmo que outro gênero textual); 2) sujeição a problemas e obstáculos que a escrita criativa promove, fazendo paralelismo às dificuldades de escrita que as ciências também possuem; 3) acesso à leitura e escrita de mais recursos vocabulares e ortográficos importantes para ampliar o repertório linguístico para a escritura acadêmica; 4) A partir da oralidade e do "repente" próprios do cordel, mesclar essas experiências com a do código escrito, lido e produzido por nós. Isso, nos permitiu a aproximação da intencionalidade entre o que pensamos, escrevemos e como o leitor nos interpreta; 5) Possibilitar uma ida além do valor semântico das palavras experimentadas em sala de aula, provocando-lhes uma significância interpretativa e intencional, observando seus usos sociais, na escrita poética e na escrita acadêmica; 6) Aumentar o prazer, o deleite e a motivação em escrever, tangencialmente poesias e ciências; e 7) Refletir sobre a importância de ensinar a gostar de escrever, antes de ensinar a escrever.

Essas percepções foram importantes para a qualificação da nossa escrita acadêmica e puderam tensionar os distanciamentos entre os gêneros textuais poético e acadêmico, reconhecendo suas especificidades, contudo, entendendo que seus usos sociais e acadêmicos podem ser transversalizados sob diversas e potentes possibilidades.

\section{Referências}

ACADEMIA Brasileira de Literatura de Cordel - ABLC. Métricas do cordel. 2016. Disponível em:< http://www.ablc.com.br/metricas.html> Acesso em: 10 ago. 2016.

APPEL-SILVA, M.; WENDT, G. W.; ARGIMON, I. I. de L. A teoria da autodeterminação e as influências socioculturais sobre a identidade. Psicologia em Revista, Belo Horizonte, v. 16, n. 2, p. 351-369, ago. 2010.

BAKHTIN, M. Estética da criação verbal. São Paulo: Martins Fontes, 1997. 512 p.

BEZERRA, J. F. O trabalho com o gênero textual cordel para desenvolver a leitura, escrita e reescrita. In: SEMINÁRIO NACIONAL SOBRE ENSINO DE LÍNGUA MATERNA E ESTRANGEIRA E DE LITERATURAS - SELIMEL, 9., 2015, Campina Grande. Anais... Campina Grande: Editora da UFCG, 2015. p. 1-14. 
FISCHER, R. M. B. Escrita acadêmica: arte de assinar o que se lê. In: COSTA, M. V.; BUJES, M. I. E. (Orgs.) Caminhos investigativos III: riscos e possibilidades de pesquisar nas fronteiras. Rio de Janeiro: DP\&A, 2005. p. 117-140.

FONSÊCA, A. V. de L.; FONSÊCA, K. S. B. Contribuições da literatura de cordel para o ensino de cartografia. Geografia, Londrina, v. 17, n. 2, p. 123-132, jul.-dez. 2008.

PEREIRA, M. V. A escrita acadêmica: do excessivo ao razoável. Revista Brasileira de Educação, Rio de Janeiro, v. 18, n. 52, p. 213-244, jan.-mar. 2013.

SILVA, S. P. da; ARCANJO, J. G. A literatura de cordel e o ensino de ciências: uma linguagem alternativa na promoção da reflexão socioambiental. Revista Virtual P@rtes, São Paulo, n. 15, 2012. Disponível em: <http://www.recantodasletras.com.br/artigos/ 3932234>. Acesso em: 10 jun. 2016.

SILVA FILHO, W. S. da. O uso da literatura de cordel como texto auxiliar no ensino de ciências do ensino fundamental da educação básica: uma abordagem quantitativa. 2010. 88 f. Dissertação (Mestrado em Ensino de Ciências e Matemática) - Universidade Luterana do Brasil, Teresina, 2010. VITÓRIA, M. I. C.; CHRISTOFOLI, M. C. P. A escrita no ensino superior. Educação, Santa Maria, v. 38, p. 41-54, jan.-abr. 2013. doi: http://dx.doi.org/10.5902/198464445865.

ZABALZA, M. Á. Diários de aula: um instrumento de pesquisa e desenvolvimento profissional. Porto Alegre: Artmed, 2004. 160 p.

Submetido em 19 de dezembro de 2017. Aprovado em 9 de março de 2018. 